\title{
Assessment Practices of Secondary School Mathematics Teachers in Guraghe Zone
}

\author{
Lemi Moges Mengesha, Solomon Zerfu Degefa \\ Department of Mathematics, College of Natural and Computational Science, Wolkite University, Wolkite, Ethiopia
}

Email address:

lemi@wku.edu.et(L. M. Mengesha),sol.zerfu@gmail.com (S. Z. Degefa)

\section{To cite this article:}

Lemi Moges Mengesha, Solomon Zerfu Degefa. Assessment Practices of Secondary School Mathematics Teachers in Guraghe Zone. Pure and Applied Mathematics Journal. Vol. 10, No. 3, 2021, pp. 77-83. doi: 10.11648/j.pamj.20211003.12

Received: June 7, 2021; Accepted: July 16, 2021; Published: July 27, 2021

\begin{abstract}
This paper was intended to examine mathematics teacher's practices of assessment techniques used in secondary schools in Guraghe Zone and attempt to explore methods of assessment used by mathematics teachers, nature of feedback provided to student and the support provided by school authorities to enable them undertake assessment effectively. For this study, mixed research approach, inferential statistics and descriptive survey method would be employed; both quantitative and qualitative data were gathered through questionnaire, document analysis, FGD and interviews. The total sample sizes of the study were 377 students and all mathematics teachers in the selected schools. In addition thirteen school principals were interviewed. In the selection of the sample population, stratified sampling, systematic random sampling and purposive samplings were used. Thus, the findings indicate that, the overall respondents' perception towards practices of continuous assessment has mean 3.630 and standard deviation 1.063 which is medium perception. In addition to this, the result showed that the first challenging step to implement Continuous assessment is large class size; the second is lack of in-services training, the third is it takes time and the last challenging step is shortage of teaching materials. Study showed that most of the teachers use the traditional feedback mechanism for continuous assessment which is not recommendable and had to use the enhanced feedback to encourage the learners' capacity. So, concerned bodies of the zone education office and schools should give support by providing teaching materials and giving training for teachers in order to increase and develop their assessment practices in theimplementation Continuous assessment.
\end{abstract}

Keywords: Assessment, Challenge, Feedback

\section{Introduction}

\subsection{Background of the Study}

In recent years, assessment of student achievement has received the attention of teachers, parents, researchers and education systems. In addition, assessment outcomes are widely used to inform policy-making and decisions about educational reform [11]. This attention has highlighted assessment as integral to the teaching and learning process. Current assessment practices need to reflect changes based on new understandings of learning theories, new curricula that are being developed, new knowledge and skills that are necessary for the $21^{\text {st }}$ century and the accountability requirements of systems and governments. In this respect assessment of student achievement is changing as today's students face a world that demands new knowledge, skills and behaviors' that have not yet been defined [1]. Students, in this fast and ever changing context, need not only develop deep understandings of disciplines but also develop the ability to analyze, synthesize and make inferences as well as think critically and solve problems. Assisting students to develop these knowledge, skills and behaviors' and become life-long learners requires changes in the assessment processes at the school and classroom level. Several assessment formats might be combined to create equal opportunities for male and female students to demonstrate their mathematical competence in a summative assessment [12].

Mathematics is a fundamental tool that is used in our daily life to solve physical problems we face. Due to this mathematics has been considered as basic subjects in a school curriculum. More mathematics lessons are likely to be taught in schools and colleges throughout the world than any 
other subject [2]. However, results of the standard tests and evaluations revealed that students do not perform to the expected level.

Assessment is not merely testing [3]. It is a process through which the quality of an individual's work or performance is judged. To overcome this, it will be much more helpful if the assessment is employed on a continuous basis using different strategies.

In relation to school setting, assessment as any procedure or activity that is designed to collect information about the knowledge, attitude, or skills of the learner or group of learners [4]. Thus, in the context of education, assessment can be defined as a predetermined process through which the quality of a student's performance in the three domains of educational objectives (cognitive, affective, and psychomotor) is judged. Assessment of students learning of curriculum contents in the area of knowledge, skills, and values is a major pre-occupation of many educational reforms.

Similarly, research findings documented that CA is a good practice for improving students' performance, monitoring students' learning progress, improving methods of teaching, motivating and grading students' achievement $[5,6]$. Thus, to ensure effective teaching of subject matter and to help students acquire the required knowledge, skill and attitude every teacher should maintain good practice continuous assessment. Significant advances have been made within the field of mathematics education in conducting both formative and summative assessments but that these advances have not made a comparable impact on learning [15]. Perception towards continuous assessment is medium and attention should be given to the perception of teachers [7]. Generally, most the researchers indicated that the current status of CA is only a symbol and not practiced well to enhance the quality of education.

\subsection{Statement of the Problem}

Teaching approaches should emphasize understanding rather than memorization and teachers should assess for understanding rather than surface knowledge and recall of facts [4]. Assessment should be able to reveal the quality of students' understanding and thinking as well as specific content or processes.

Frequency of assessment is also considered important in facilitating retention of material learnt. Assess all aspects of mathematical competence, not only certain aspects that are easier to assess [13]. Since retention of material is one of an important component of master learning [8], it can be inferred that frequent testing contributes to mastery learning. In line with this teachers perceived classroom assessment as tests that they give to their students at specific time intervals [9]. Moreover, as they perceive classroom assessment as tests, they showed a limited ability to use different methods and tools to assess their students.

There are various methods that can be used to assess students learning such as portfolios, projects, performance assessment such methods offer rich information about teaching and learning. Taking all of these in to account, the $\mathrm{MoE}$ in our country introduced continuous assessment at the different level of the educational institutions. To better target assessments to individual levels of performance, we need more richness and variety in assessment formats [12]. In Ethiopian context, the New Education and Training policy calls for application of Continuous Assessment in academic and practical subjects for the benefit of ascertaining the formation of all round profile of students at all levels [10]. Not only culture and language need to be taken into consideration but also how students respond to feedback [14].

In our context, however, there is no research evidence that tells us about the status of assessment practices and the feedback mechanisms that mathematics teachers are using in secondary schools in Guraghe Zone. It is worthwhile, therefore, as part of the investigator it is important to examine mathematics teacher's use of continuous assessment in Guraghe Zone.

\subsection{Objective of the Study}

The study was having the following general and specific objectives. The main objective of the study was to explore the CA practices of mathematics teachers in the class room.

The specific objectives of the study were:

1) To determine the status of CA practices that mathematics teachers' use.

2) To examine how mathematics teachers' use information generated from classroom assessment.

3) To identify the feedback mechanism that mathematics teachers prefer to use.

4) To explore the factors those affect the effective practices of continuous assessment in mathematics at secondary schools of Guraghe Zone.

\subsection{Significance of the Study}

The findings of this study would be important for different concerned educational partners that were found at various levels. Therefore, the outcome of the study would provide information to higher officials and policy makers about the existing status of continuous assessment and the areas to be considered in the process of making policy decisions. This study would also give information to school principals on how continuous assessment was being carried out in the secondary schools and the mechanisms to make improvements in the area. Furthermore, it would suggest alternative solutions to be used by teachers, students and principals to minimize the problems in the implementation of continuous assessment. Finally, the study might be used as an additional source of information for further studies.

\subsection{Delimitations of the Study}

The following delimitations were important to this study. The findings of the study were delimited to Guraghe zone secondary schools mathematics teachers and were only applicable for grade 9 and 10 mathematics teachers and 
students. The validity and reliability of the data collected were dependent on the information given by the participant mathematics teachers and students.

\subsection{Scope of the Study}

The scope of the study was limited to some selected secondary schools in Guraghe zone. Moreover, the study was delimited to assess the state of practices, feedback mechanisms and factors associated in implementing continuous assessment in teaching mathematics in the zone.

\section{Research Methods}

\subsection{Research Design and Approach}

This research has an aim of examining the practices of mathematics teacher's use of formative assessment in their classroom teaching. The study was conducted in Guraghe zone. The research approach was a mixed type which mean both qualitative and quantitative. The study would employ both inferential statistics and descriptive survey method.

\subsection{Population and Sampling}

Based on the information obtained from the educational office of the zone, there are a total of 89 high schools (grade $9-10^{\text {th }}$ ) in Guraghe zone. For this study the researchers would use stratified sampling to select the schools from the zone. By using stratified sampling the zone can be divided into thirteen woredas and four administrative cities. Therefore schools from each woredas can be considered as one stratum and those from city administrative as the second stratum. Then the selection of the schools was dependent on the proportion of the size of the population. From these schools students would be selected using multi-stage sampling. School principals and all mathematics teachers were selected purposively.

\subsection{Participants and Sampling Technique}

The sampling frame of the study was all officially registered 20,458 students, all mathematics teachers and 13 principals of the above listed schools. Purposive sampling techniques were used to select teachers and schools principals.

The total number of students in all the selected secondary high school in the Guraghe zone is 20,458. Hence; it is difficult to include all of them as data sources. The size of sample should neither be excessively large nor too small. It should be optimum. An optimum sample is one which fulfills the requirements of efficiency, representativeness, reliability and flexibility.

Therefore based on the number of students the sample sizes of each school were obtained proportionally. Thus, 377 students were selected to participate on the study. Moreover, all mathematics teachers and 13 school principals would be selected purposively. There would be three focus group discussions for teachers selected randomly. Moreover school principal would be selected purposively and interviewed.

\subsection{Data Type and Source}

\subsubsection{Data Type}

Qualitative and quantitative data types were gathered from primary data sources on the issue of teachers' practices of continuous assessment in mathematics teaching. Secondary data types also were used from documents or portfolio of teachers.

\subsubsection{Source of Data}

Having a real source of data in the process of the study was unquestionable to address the basic questions. To have thick and valuable data, both primary and secondary sources of data were used in this study.

\section{(i) Primary Sources}

Primary sources were principals, secondary school mathematics teachers, secondary school students. Primary sources would be helping the researchers to get firsthand information about the issue under study.

\section{(ii) Secondary Sources}

Secondary data was obtained from documents. In this regard, an assessment of documents related to the areas of the study would be consulted at the selected secondary schools. These documents include student mark list and teachers' daily assessment reports.

\subsection{Data Collection Instruments}

In order to achieve the objectives of the study, the data were collected through questionnaire, document analysis and interview. To triangulate the data FGD would be made and observation of students' exercise book to identify the feedback mechanism which teachers prefer to use was conducted.

\subsection{Data Analysis Procedure}

This study was conducted using both inferential statistics and descriptive survey design and the researchers attempt to investigate and find a solution for the research questions. Therefore, the researchers were used different analysis procedures like frequency, percentages and T test. Thus SPSS would be used to analyze the quantitative data that would be collected by the questionnaire. Accordingly, the interview, FGD and observational data were presented in narrative form.

\subsection{Procedure of Data Collection}

The data gathering instruments were preparing in English language for teachers, school principals, and for the students. The data was collected through questionnaires', interview, observation, and focus group discussion. The researchers making the instruments of data collection of the study clear to all of the respondents to avoid confusion and get reliable information. 


\subsection{Validity of the Instrument}

The instrument had faced and constructs validities. The instrument was validated by the researchers' supervisor and other lecturers who are experienced in teaching in the Wolkite University. Based on the proper study, identification of problem areas and further modifications made and final instrument for the study was drawn up.

\subsection{Reliability of the Instrument}

In order to test the reliability of the instrument a pilot test was conducted in selected secondary schools those which are not in the sample of the study. Pilot test were collected and analyzed and the questioner was reliable.

\section{Result and Discussion}

This research aimed to examining the continuous assessment practices of secondary school mathematics teachers. The findings of the study were presented, analyzed, and interpreted in order to answer the identified research questions.

\subsection{Characteristics of Respondents}

Table 1. Characteristic of the respondents by their age.

\begin{tabular}{lll}
\hline Age & Frequency & Percent \\
\hline 20-25 years & 13 & 16.3 \\
26-30 years & 19 & 23.8 \\
31-35 years & 27 & 33.8 \\
36-40 years & 10 & 12.5 \\
41 and above & 11 & 13.8 \\
\hline
\end{tabular}

As the above table 1 showed the respondents' $13(16.3 \%)$ are aged between 20 to 25 years old, $19(23.8 \%)$ are aged between 26 to 30 years old, $27(33.8 \%)$ are aged between 31 to 35 years old, $10(12.5 \%)$ are aged between 36 to 40 years old and $11(13.8 \%)$ are 41 and above years old. Thus, respondents' have a mean age of 2.84 and standard deviation of 1.247 years old.

Table 2. Characteristic of the respondents by their experience.

\begin{tabular}{lll}
\hline Years of experience & Frequency & Percent \\
\hline 0-3 years & 12 & 15.0 \\
4-7 years & 34 & 42.5 \\
8-11 years & 12 & 15.0 \\
12-16 years & 17 & 21.3 \\
17 and above & 5 & 6.3 \\
\hline
\end{tabular}

Table 2 discloses that $12(15.0 \%)$ teachers have 0 to 3 years of service, $34(42.5 \%)$ teachers have 4 to 7 years of service, $12(15.0 \%)$ teachers have 8 to 11 years of service, 17 $(21.3 \%)$ teachers have 12 to 16 years of service and Some 5 $(6.3 \%)$ of them 17 and above year of teaching experience have a mean years of experience 2.61 and standard deviation of 1.164 .

Table 3. Teaching load of respondents.

\begin{tabular}{lll}
\hline Teaching load & Frequency & Percent \\
\hline below 10 & 12 & 15.0 \\
$10-15$ & 37 & 46.3 \\
$16-21$ & 27 & 33.8 \\
22 and above & 4 & 5.0 \\
\hline
\end{tabular}

Table 3 discloses that $12(15.0 \%)$ teachers have teaching load credits of below 10, $37(46.3 \%)$ teachers have a teaching load of 10 to 15 credits, $27(33.8 \%)$ teachers have 16 to 21 credits years and Some $4(5.0 \%)$ of them 22 and above teaching load credits with a mean of teaching load 2.2875 and standard deviation of 0.78262 .

\subsection{Teachers Assessments Methods Used to Assess their Students}

Table 4. Teachers' continuous assessment methods.

\begin{tabular}{|c|c|c|c|c|c|c|c|c|c|}
\hline № & Assessment methods & Alv & & Sor & & Wh & sary & Not & \\
\hline & & $\mathbf{F}$ & $\%$ & $\mathbf{F}$ & $\%$ & $\mathbf{F}$ & $\%$ & $\mathbf{F}$ & $\%$ \\
\hline 1 & Class work & 35 & 43.8 & 26 & 32.5 & 19 & 23.8 & 0 & 0 \\
\hline 2 & Home work & 30 & 37.5 & 24 & 30.0 & 26 & 32.5 & 0 & 0 \\
\hline 3 & Observation & 43 & 53.8 & 23 & 28.8 & 14 & 17.5 & 0 & 0 \\
\hline 4 & Oral question & 54 & 67.5 & 20 & 25.0 & 6 & 7.5 & 0 & 0 \\
\hline 5 & Group discussion & 25 & 31.3 & 31 & 38.8 & 24 & 30.0 & 0 & 0 \\
\hline 6 & Presentation & 13 & 16.3 & 22 & 27.5 & 45 & 56.3 & 0 & 0 \\
\hline 7 & Reflection & 4 & 5.0 & 33 & 41.3 & 43 & 53.8 & 0 & 0 \\
\hline 8 & Peer assessment & 6 & 7.5 & 14 & 17.5 & 41 & 51.3 & 19 & 23.8 \\
\hline 9 & Self-assessment & 19 & 23.8 & 12 & 15.0 & 30 & 37.5 & 19 & 23.8 \\
\hline 10 & Project work & 0 & 0 & 4 & 5.0 & 53 & 66.3 & 23 & 28.8 \\
\hline 11 & Quizzes & 0 & 0 & 22 & 27.5 & 45 & 56.3 & 13 & 16.3 \\
\hline 12 & Test & 0 & 0 & 35 & 43.8 & 45 & 56.3 & 0 & 0 \\
\hline 13 & Asking and answering question & 31 & 38.8 & 19 & 23.8 & 30 & 37.5 & 0 & 0 \\
\hline 14 & Exam & 0 & 0 & 64 & 80 & 16 & 20 & 0 & 0 \\
\hline
\end{tabular}

As the results obtained put in Table 4 is interpreted as follows: As indicated in Table 4, most of the mathematics teachers' 54 $(67.5 \%)$ use oral question as one of the most frequently used assessment technique. This was followed by observation by 43
(53.8\%) and class work $35(43.8 \%)$ as means of continuous assessment. Furthermore, they pointed out that they sometimes used mid-exam 64 (80\%), test 35 (43.8\%), reflection 33 (41.3\%) and asking and answering question 30 (37.5\%). 


\subsection{Challenges to Implement Continuous Assessment to Teachers}

In the figure below shows the factors challenges to implement continuous assessment to the teachers. So, the result shows that the first factor challenges is large class size $(86.25 \%)$, the second is lack of additional training $(68.75 \%)$, the third is time taking $(58.75 \%)$ and the last challenging step is shortage of teaching materials $(47.50 \%)$.

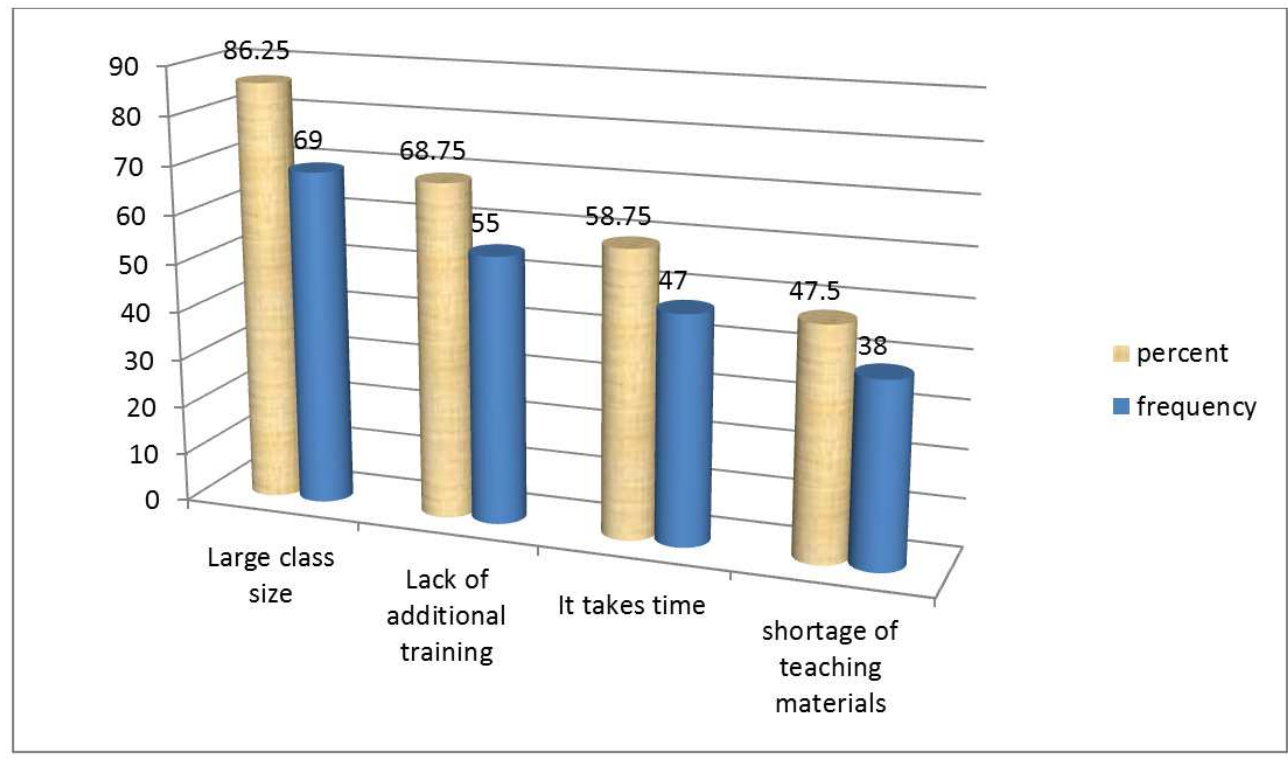

Figure 1. Response on factors Challenges to implement continuous assessment.

\subsection{The Extent School Administration helps Teachers in Implementing Continuous Assessment}

Table 5. Response to the extent of continuous assessment.

\begin{tabular}{lll}
\hline Items & Frequency & Percent \\
\hline Very High & 3 & 3.8 \\
High & 6 & 7.5 \\
Average & 45 & 56.3 \\
Below Average & 21 & 26.3 \\
Not at all & 5 & 6.3 \\
Total & 80 & 100.0 \\
\hline
\end{tabular}

Table 5 shows the frequency and percent of the extent school administration helps teachers in implementing continuous assessment with measuring by Likert scales very high, high, average, below average and not at all. So, the result shows $56.3 \%$ of the respondents are get help average in implementation continuous assessment from school administration, $26.3 \%$ of the respondents are get help below average in implementation continuous assessment, $6.3 \%$ of the respondents are not get help in implementation continuous assessment from school administration. So the school administration must be gave additional training and need help from the concerned body of the education bureau of the zone.

\subsection{Data Obtained from FGD About Continuous Assessment from Teachers}

FGD and interview are additional form of data collection instruments that we state to collect data about the implementation of continuous assessment. So the information that we get from FGD and interview of secondary schools teachers we got two views about continuous assessment with possible solutions.

a) The positive side of continuous assessment

If it was done correctly it helps the students more engaged for their carrier and it helps them not to miss the time with unwanted program.

b) Negative side of continuous assessment

The teachers list negative side of continuous assessment. These are school principals were used for report only, administrative interfering in academic affairs, and all duties of the assessment forwarded to clever students. So currently the negative side of continuous assessments highly reflected and enables learners simply to pass from grade to grade since they are not properly assessed therefore it harms highly the quality of education nowadays.

\subsection{Teachers Feedback Mechanisms}

The study also examines the feedback mechanism that mathematics teachers used. As a teachers stated they use different types of feedback mechanisms. The Traditional Feedback was given in the form of oral, ticks for correct solutions and crosses for incorrect solutions, and circling of mistakes which offers little information about students' learning processes and enhanced Feedback, which included constructive written feedback about their mathematics work and also including tutors and its result in promoting their learning in mathematics. But currently most of the teachers used Traditional Feedback due to the factors stated above.

As we got information from interview of teachers and FGD almost all teachers apply traditional way of feedback mechanism to assess continuous assessment. Additionally the 
students' response on the teachers' feedback mechanisms used currently stated in table 6 below.

Table 6. Students' response on feedback mechanism.

\begin{tabular}{lll}
\hline Items & Frequency & Percent \\
\hline Traditional Feedback & 323 & 86 \\
Enhanced Feedback & 54 & 14 \\
\hline
\end{tabular}

From the table $323(86 \%)$ of the students responded that the teachers use traditional feedback and 54 (14\%) of the students responded that the teachers use enhanced feedback mechanisms.

\subsection{The Problems Encountered During the Implementation of Continuous Assessment}

Teachers' implementation of continuous assessment can be influenced by different constraints.. Large number of students, Time constraints and shortage of time is a challenge for them to effectively carry out continuous assessment. In interview the female teacher is said, "We meet our students only for 40 minutes; 10 minutes for short note. So with this time we are expected to introduce what they are going to learn and clarify the concept and main idea of the lesson and etc......the only way that we can assess our students mostly is by midterm and final exams."

\subsection{Possible Solutions Suggested by the Respondents}

Ministry of Education in our country schools should consider their enrollment number with respect to their capacity, so that the number of students would be decreases into manageable one. Sufficient instructional material needed to be made available for all teachers' availability of necessary materials such as text books, reference materials, and teaching aids help teachers to carry out each process of continuous assessment effectively. Pedagogical center should be well organized the necessary teaching materials like mathematics tools and 3D object should be full filled as well as subject wise extra teachers should be employed, training and encouragements to have be given to teachers.

\section{Conclusion and Recommendation}

\subsection{Conclusion}

The main purpose of this study was to examine the Assessment Practices of Secondary School Mathematics Teachers.

The study was proposed four main research questions. These are:-

1) What is the status of continuous assessment practices in mathematics class at secondary schools?

2) How do mathematics teachers' use information generated from classroom assessment?

3) What forms of assessment feedback mechanisms do mathematics teachers prefer to use?

4) What are the factors that those affect the effective practices of continuous assessment in mathematics at secondary schools of Guraghe Zone?

The major findings of this study were:

1) Some of the respondents $37(46.3 \%)$ disagreed that assessment has minor impact on teaching and learning, and $32(33.6 \%)$ agreed that assessment has minor impact on teaching and learning and the remaining are undecided.

2) As indicated in the study, most of mathematics teachers use oral questions, observation and class work as continuous assessment to gather information from their students. Furthermore, they point out that they sometimes used mid-exam, test and quizzes as continuous assessment to assess their students.

3) The study states that, most of mathematics teachers use the traditional feedback mechanism for continuous assessment.

4) Almost all $74(92.6 \%)$ of the respondents agreed that assessment feedback is useful in enhancing students' performance and $40(50.1 \%)$ respondents agreed on the statement assessment increases the workload for teachers'. Lastly, majority of the respondents 52 $(65.1 \%)$ agreed on the statement continuous assessment is time consuming. Similarly, minority of the respondents $19(23.8 \%)$ disagreed on the statement continuous assessment is time consuming and some of them undecided on the idea.

5) Most of the respondents agreed that, large class size 69 $(86.25 \%)$ is the most factors that affect the effective practices of continuous assessment in mathematics. They also state that lack of additional training (willingness) 55 (68.75\%) about continuous assessment is a second factor and lastly, time consuming 47 $(58.75 \%)$ and shortage of teaching material are also the factors that affect the practices of continuous assessment in mathematics class.

\subsection{Recommendation}

Based on the above summary and conclusion, the researchers suggest the following possible measures so that the present problem concerning practices of the implementation of continuous assessment in zone could be minimize.

1) The zone or the each secondary school should create conducive environment and give support by arranging and giving in-service training for teachers in order to increase and develop their positive attitude towards practices of continuous assessment.

2) Practicing continuous assessment in class room has a great importance for students since they devote their time in academic issue and they share their knowledge with each other.

3) Secondary school teachers should get additional training and awareness how they implement continuous assessment.

4) Teachers' should have to use the enhanced feedback mechanism to increase the performance and knowledge of students towards the subject matter.

5) The stake holder of education should decrease the number of students in the class to assure the quality of education. 
6) Finally, further research should be conducted on a zone including all secondary schools science teachers since it could be difficult to generalize the current finding to all teachers of the zone.

\section{References}

[1] Segers, M., Dochy, F. \& Cascallar, E. (eds). (2003). Optimising New Modes of Assessment: In Search of Qualities and Standards. Kluwer Academic Publishers, Dordrecht.

[2] Orton, A., Orton, D., \& Frobisher, L. J. (2004). Insights into teaching mathematics. Continuum International Publishing Group.

[3] Osokoya, I. O, (1996). Writing and Teaching History: A Guide to Advanced Study, Laurel Educational Publishers, and Ibadan.

[4] Greaney V (2001). Using Assessment to improve the quality of Education Paris: UNESCO International Institute for Education Planning.

[5] Birhanu. M, (2004). Teachers assessment of students performance in selected high schools of Arsi zone with Emphasis on continuous assessment." M. A Thesis Addis Ababa university.

[6] Desalegn Chalchisa, (2001). An evaluation of the syllabus of teacher Training Institute in preparing Training to implement continuous assessment in the first cycle primary schools, proceedings of the national conference quality of primary education in Ethiopia.

[7] Lemi Moges Mengesha, Solomon zerfu Degefa, Secondary School Mathematics Teachers Perceptions on Continuous
Assessment in Guraghe Zone. Research on Humanities and Social sciences ISSN 2224-5766 (Paper) ISSN 2225-0484 (Online) Vol. 11, No. 1, 2021 doi: 10.7176/RHSS/11-1-02.

[8] Wolf, D., Bixby, J., Glenn, j. \& Gardner, H. (eds) (1991) To Use Their Minds Well: investigating new forms of student assessment (Washington, DC, American Educational Research Association).

[9] Susuwele-Banda, W. J. (2005). Classroom Assessment in Malawi: Teachers Perceptions and Practices in Mathematics, Doctoral Dissertation, Virginia Polytechnic Institute and State University. Retrieved from http://scholar.lib.vt.edu.

[10] MoE (1994) Education and Training Policy: Federal Democratic Republic of Ethiopia, Addis Ababa. ST. GEORGE PRINTINGPRESS.

[11] Nortvedt, G. A. (2018). Policy impact of PISA on mathematics education: The case of Norway. European Journal for Psychology in Education, 33 (3), 427-444.

[12] Leder, G., \& Forgasz, H. J. (2018). Measuring who counts: Gender and mathematics assessment. ZDM Mathematics Education, 50 (4), 1-11.

[13] Hoogland, K., \& Tout, D. (2018). Computer-based assessment of mathematics in the 21st century: Pressures and tensions. ZDM Mathematics Education, 50 (4), 1-12.

[14] Heritage, M., \& Wylie, C. (2018). Reaping the benefits of assessment for learning: Achievement, identity and equity. ZDM Mathematics Education, 50 (4), 1-13.

[15] Burkhardt, H., \& Schoenfeld, A. (2018). Assessment in the service of learning: Challenges and opportunities. ZDM Mathematics Education, 50 (4), 1-15. 